\title{
nordon
}

\section{WEEE Plastics Recycling}

A guide to enhancing the recovery of plastics from waste electrical and electronic equipment

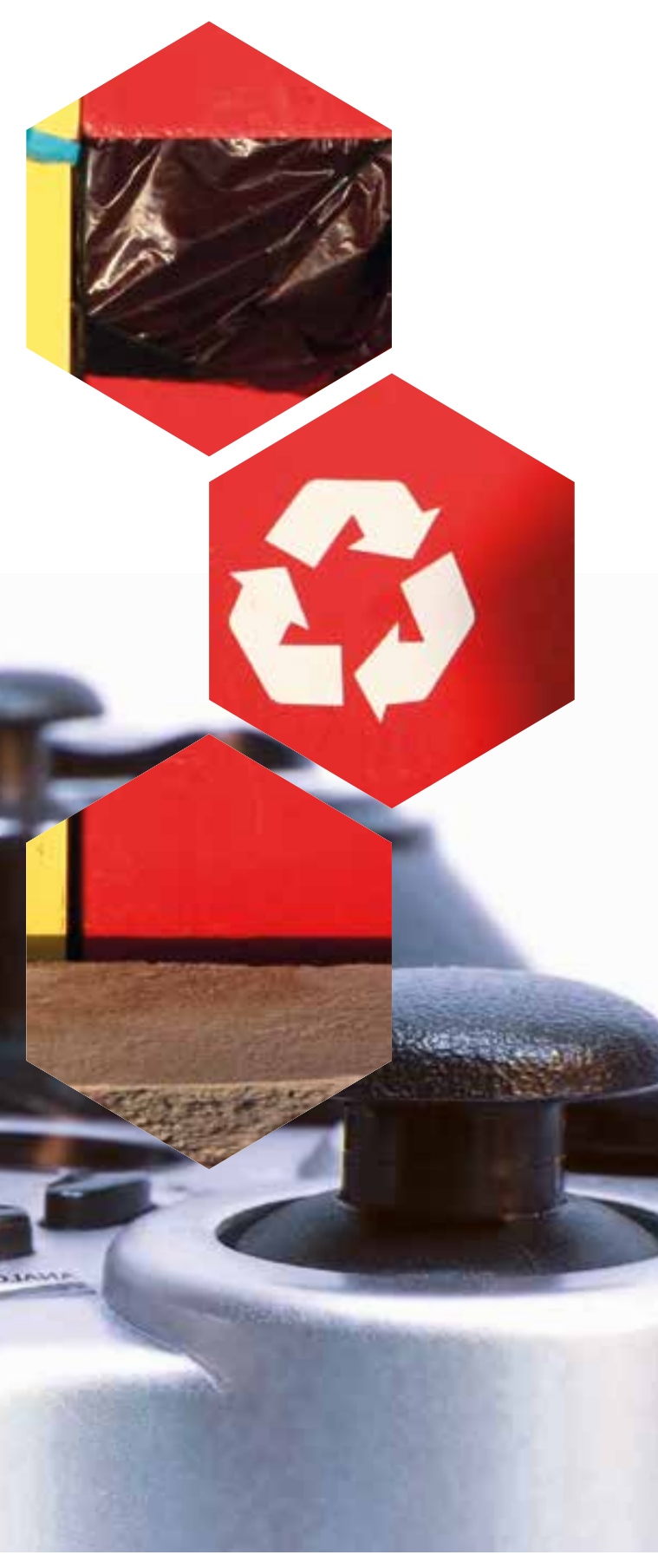




\section{WEEE Plastics Recycling}

A guide to enhancing the recovery of plastics from waste electrical and electronic equipment

ISBN 978-92-893-3954-4 (PRINT)

ISBN 978-92-893-3955-1 (PDF)

http://dx.doi.org/10.6027/ANP2015-713

ANP 2015:713

(C) Nordic Council of Ministers 2015

Authors: Baxter, John. Wahlstrom. Margareta.

Castell-Rüdenhausen, Malin Zu. Fråne, Anna.

Layout: Gitte Wejnold

Cover photo: SignElements

Photo: SignElements

Print: Rosendahls-Schultz Grafisk

Copies: 100

Typeface: Meta LF

Paper: Munken Polar

Printed in Denmark

www.norden.org/en/publications

\section{Nordic co-operation}

Nordic co-operation is one of the world's most extensive forms of regional collaboration, involving Denmark, Finland, Iceland, Norway, Sweden, and the Faroe Islands, Greenland, and Åland.

Nordic co-operation has firm traditions in politics, the economy, and culture. It plays an important role in European and international collaboration, and aims at creating a strong Nordic community in a strong Europe.

Nordic co-operation seeks to safeguard Nordic and regional interests and principles in the global community. Common Nordic values help the region solidify its position as one of the world's most innovative and competitive.

\section{Nordic Council of Ministers}

Ved Stranden 18

DK-1061 Copenhagen K

Telefon (+45) 33960200

www.norden.org 


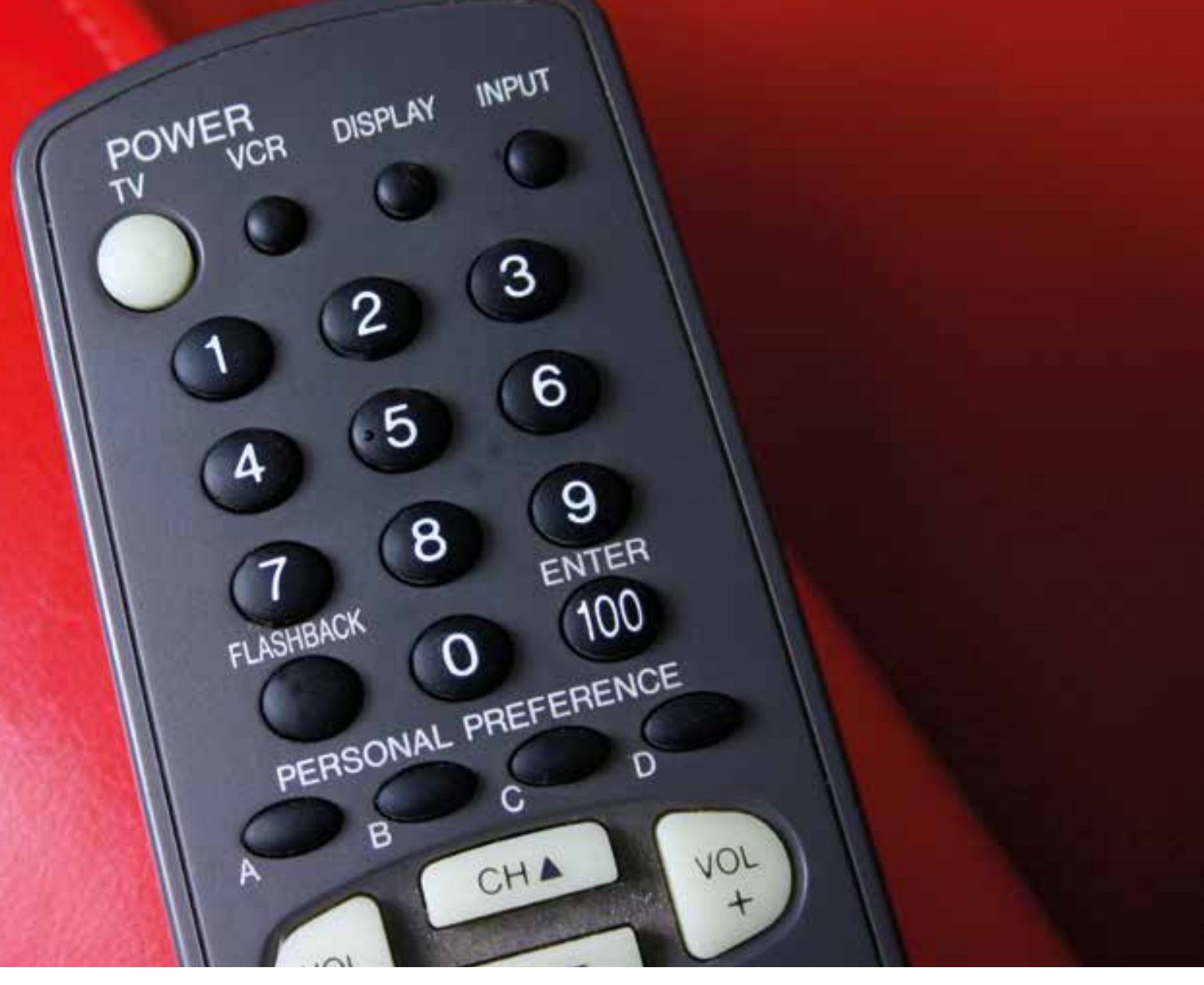





\section{WEEE Plastics Recycling}

A guide to enhancing the recovery of plastics from waste electrical and electronic equipment

Baxter, John. Wahlstrom. Margareta. Castell-Rüdenhausen, Malin Zu. Fråne, Anna. 


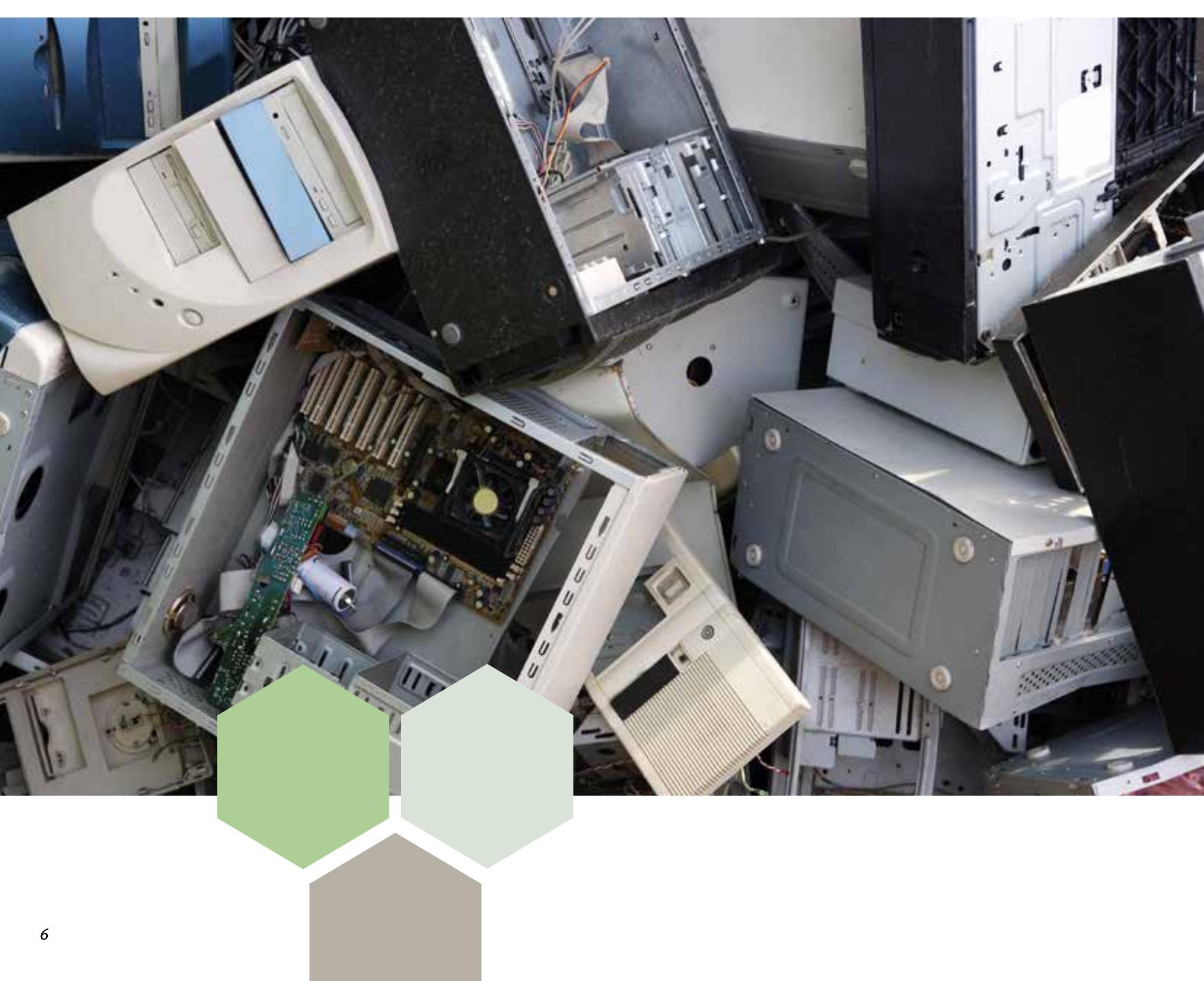




\section{About this guide}

This Guide arises from a project entitled: "Nordic plastic value chains Case WEEE (Waste Electrical and Electronic Equipment)", which is one of six projects within the Waste category of the Nordic Prime Ministers' Green Growth initiative, The Nordic Region - Leading in green growth. The project was undertaken by a consortium of research organisations across the Nordic region, with direct input from Norway, Sweden, Denmark, Finland and Iceland.
The purpose of this guide is to inform and assist different stakeholders in the Nordic region to enhance the recycling of plastic materials from WEEE. The Guide outlines some of the main project conclusions in the form of basic recommendations to various parties: consumers, authorities and policy-makers, recyclers and waste operators, and electronics producers.
Further details on the project can be found at: www.norden. org/greengrowth and in the web magazine Green Growth the Nordic Way at www.nordicway.org 


\section{About WEEE plastics and recycling}

Around 400000 tonnes of WEEE is collected across the Nordic region each year. Collection rates are high by worldwide standards. Yet, further improvements could be made, particularly for smaller items that are not necessarily recognised as electronic waste. Overall recycling rates are also high, with around $85 \%$ of collected WEEE subject to material recycling.
Yet for the estimated 70000 tonnes of WEEE which takes the form of plastics, the picture regarding recycling is less clear and much less positive. It's thought that well under $25 \%$ of this material is recycled. Hazardous materials in plastics present some barriers, but much of the shortcoming in recycling can be attributed to fairly straightforward technical and economic problems.
There is a well-established infrastructure for collection, transport and recycling of WEEE, also how it is funded, administered and regulated. WEEE plastics recycling could be enhanced in some ways by making this infrastructure work as intended. This is a responsibility shared across a range of different stakeholders. The Guide outlines practical steps that different parties could consider to improve matters. 


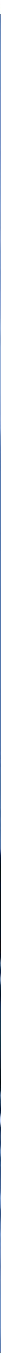




\section{Which of these items form electronic waste at the end of their lives?}

\begin{abstract}
All of them
You probably wouldn't consider disposing of a TV or refrigerator in the ordinary household waste but what about smaller items that contain electronics, such as small toys or musical greetings cards?
\end{abstract}

Huge amounts of these items end up in ordinary domestic waste each year and are landfilled or incinerated, often because people just don't recognise them as electronic waste. Electronic waste also ends up in recyclable plastic waste, which is not surprising as many items contain a lot of plastic material and could be taken for plastic products. Pay attention to hidden electronic components, such as in toys, to avoid throwing electronic waste in the wrong bin. Electronic waste ending up where it is not supposed to represents both a loss of recyclable material and might lead to pollution of other waste streams.

Your municipality or electronics retailer will have arrangements for collecting and recycling electronic waste. Take care to dispose of your electronic items properly. Look for local initiatives where small electronic items are collected, it might be at your closest supermarket or where you do your daily business.
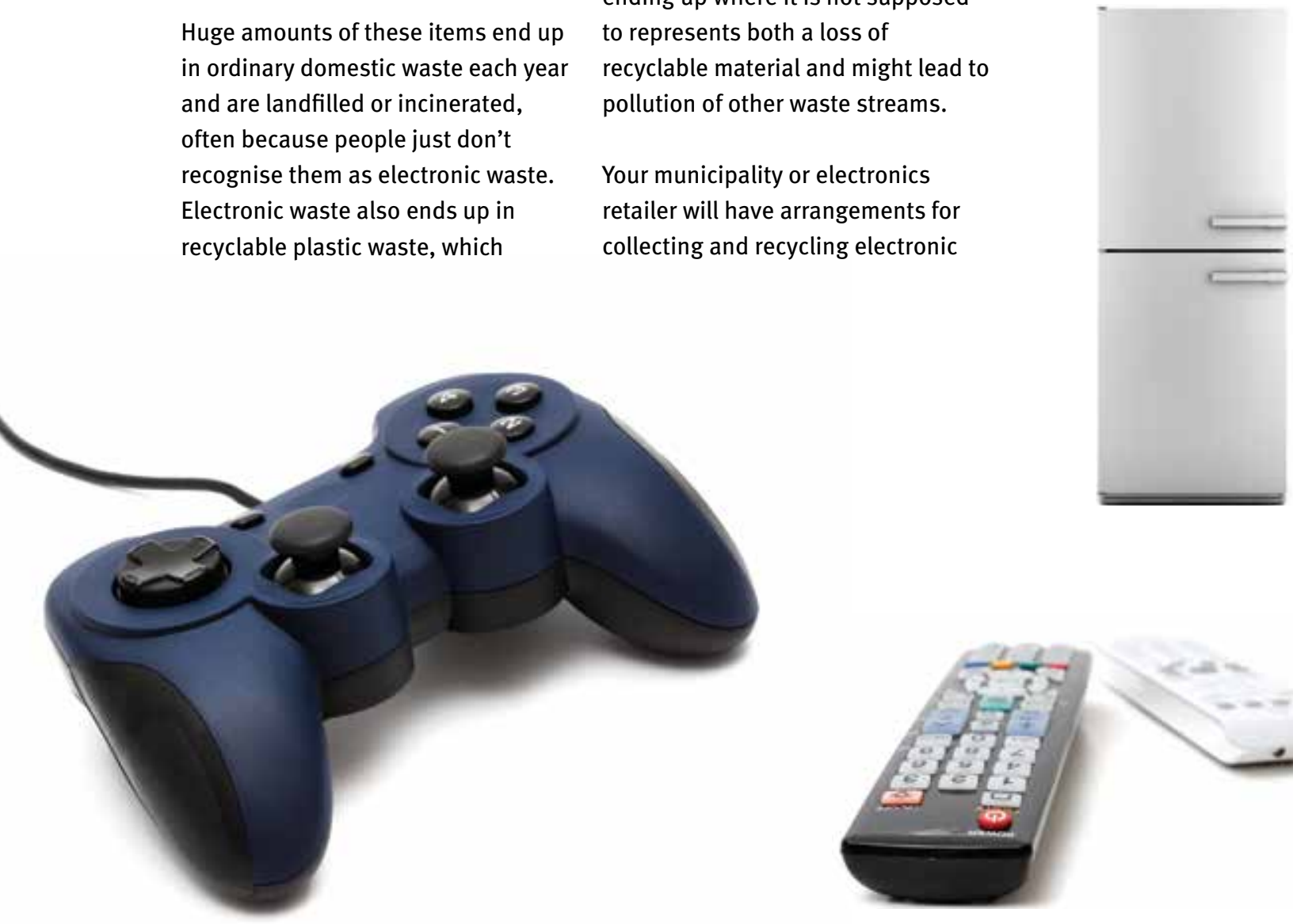


\section{Where does your electronic waste end up?}

\section{In the desk drawer?}

Then you are not alone. Large amounts of old electronic devices are piled up in society. When Norwegians were asked how many mobile phones they have stored at home the total number was estimated to be around 10 million. 60 percent of the Norwegian population has more than two mobile phones at home that are not in use.

It is tempting to think that one's old mobile phone in a desk drawer is not doing the environment any harm but it's not true. Failure to recycle the materials - including plastics - in the device means that an important resource stock remains unexploited and additional new materials have to be manufactured, which impacts severely on the environment.

Make sure your old electronic items are recycled if you don't want to reuse them. Remember that many consumers intend to reuse old electronic equipment but end up stockpiling it anyway. Retaining end-of-life products rather than submitting them for recycling can be considered to be a serious environmental problem.

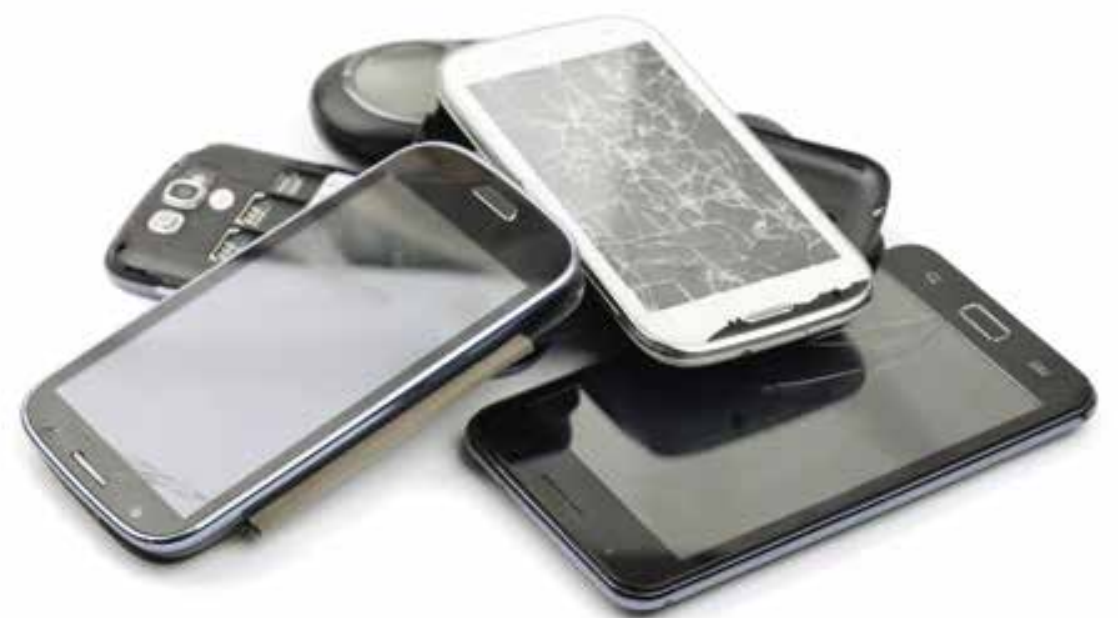




\section{WEEE plastics require higher-quality recycling than is currently standard}

\section{WEEE recycling provides good value for money \\ Nonetheless, the systems for Extended Producer Responsibility in Europe are locked into a low-cost and hence relatively low-quality treatment regime for WEEE.}

WEEE collection rates are relatively good, and overall material recycling rates are generally high. However this is predicated largely on the easy (technically straightforward, economically self-standing) recovery of certain materials, notably metals. More challenging WEEE elements, notably plastics, fare much worse and recycling rates are much lower. This is largely because of economic factors.

Simply introducing differential or additional tariffs under EPR may not be a feasible solution. Even though recycling costs are a small fraction of sales price (for many product groups), increases in such costs may well be sternly resisted by the sector.

Indirect, non-financial instruments could provide the necessary drive. A scheme of regulatory targets for collection and recycling of specific materials, over and above existing gross weight collection requirements, could drive up funding levels and hence treatment quality.

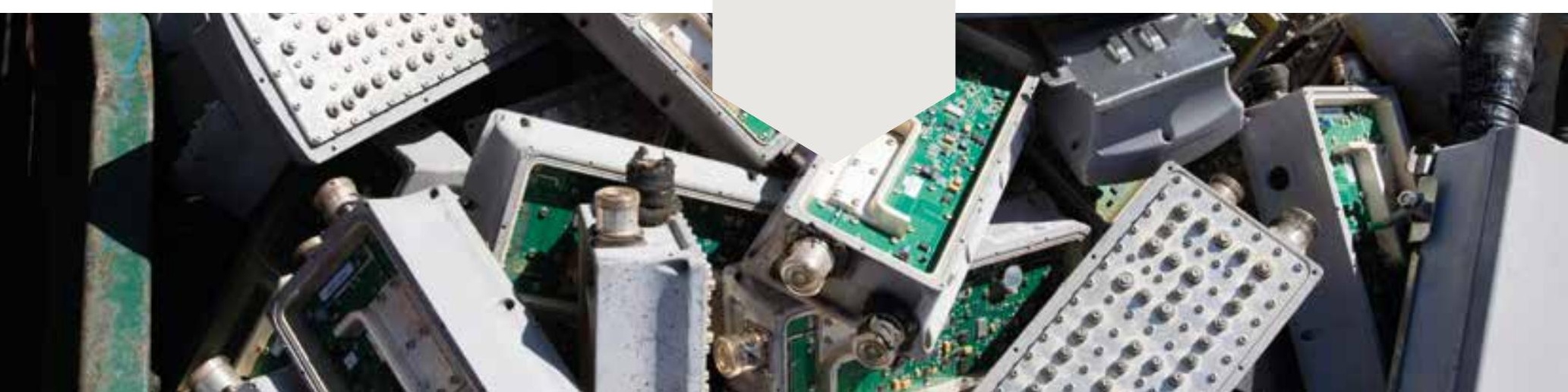




\section{WEEE must be kept in official recycling channels}

\section{WEEE plastics recycling faces a number of threats}

Probably the biggest of these is that plastics recycling is often simply never attempted.

There are numerous ways in which WEEE can be diverted from the official recycling value chain as established by Extended Producer Responsibility. A common feature of all these diverted pathways is that they entail little or no plastics recycling. There are three principal pathways:

- Consumers hoarding waste or disposing of WEEE in residual waste

- The scrap metal sector (both legal and illegal)

- The illegal export sector (including “used EEE”)

The latter probably constitutes the biggest threat. Better policing of waste exports is clearly needed and would probably be the single most important factor for keeping waste in the system. WEEE is also (dubiously) shipped as used EEE. The relevant regulations for classifying and labelling used EEE and WEEE probably need careful reexamination.

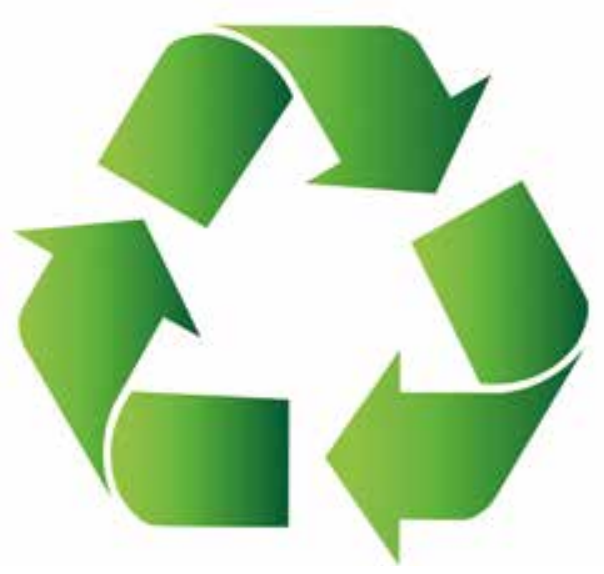




\section{Plastics recycling may benefit from a lower-tech approach}

\author{
Low-tech may be best for plastics \\ recycling quality \\ Evidence suggests that WEEE \\ treatment processes with significant \\ low-tech elements, including manual \\ disassembly and separation of WEEE, \\ can currently achieve significantly \\ better plastics recycling than \\ highly mechanised and automated \\ alternatives.
}

Lower-tech approaches carry relatively higher costs and may otherwise appear unattractive in a sector where technological advance seems vital. However WEEE plastics are especially challenging to recycle and dependent on high-quality processes.

Changes in regulation and/or the funding climate could bring plastics recycling into greater focus and possibly make low-tech, costly, yet high-quality plastics recycling much more attractive than it is at present.

Recyclers should be wary of losing their capability for low-tech WEEE recycling; it may be needed in the future.

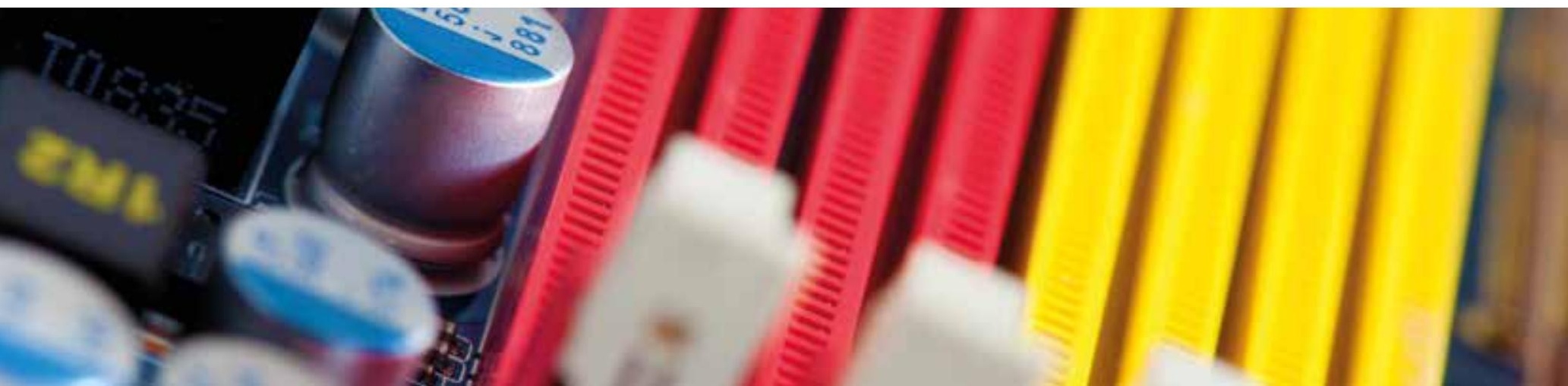




\section{Better tracking and tracing of electronic waste streams is needed}

\section{Recyclers are often acting in the \\ dark}

Facilities processing electronic waste take inputs from many sources, and these may be quite poorly characterised. For readily identifiable components such as metals this may not be a particular problem, but plastics are considerably more challenging and the isolation of hazardous materials is a particular challenge.

Relatively simple improvements could make a considerable difference:
- Upstream source-sorting of wastes (for example by municipalities or retailers)

- Tracking of waste movements to the collection / recycling point

- Supervision of material arriving at the recycler (e.g. verifying its composition)

- Labelling (including as appropriate 'smart' labelling using barcodes or RFID)

- Sampling and analysis for hazardous content when required (for instance when there is uncertainty regarding composition)
Responsibility for these actions is clearly shared between producers, upstream waste-holders, transporters and the recyclers themselves. Communication and cooperation will be essential. 


\section{Design for recycling gives environmental advantage}

\author{
"Green certification" could \\ justify effort towards better \\ product design \\ It's widely noted that there seems \\ to be little general push towards \\ design for recycling in consumer \\ electronics. However, analysis shows \\ that improved design with respect \\ to plastics, via recycled plastics \\ feedstock, and/or design to ensure \\ recyclability of products at end-of-
}

life, yields tangible environmental advantages. Product environmental impact could be reduced by $20 \%$ or more. The savings could be even greater if other components including metals are also taken into account.

A key factor is that such savings should be communicable to the market and/or consumers through product environmental declarations, and hence offer market and economic advantages. Some manufacturers are beginning to move in this direction, and the momentum will surely continue. 


\section{Informing customers is vital for product end-of-life management}

\author{
Producer responsibility costs \\ money \\ Overall, and in the long-term, \\ the financial burden of producer \\ responsibility for waste treatment \\ will be reduced via an informed \\ customer base who take the right \\ product disposal decisions from their \\ perspective. Product packaging, \\ labels on the product itself and clear \\ information on company websites \\ all present potentially low-cost
}

communication opportunities. Municipalities work closely with consumers and making waste management information easy to find for them is vital. Informing consumers is especially important for products that are not obviously regarded as electronic waste such as sport shoes with blinking lights and musical greeting cards.
At present, producer responsibility burdens are allocated to specific producers based on products put on the market. Future developments - for example in technology and labelling - could result in producer responsibility being allocated in a more specific and focused fashion, which would make it all the more important for individual producers to take steps such as those recommended here. 


\section{Summary}

- Many of the recommendations for improving the recycling of WEEE plastics are concerned with WEEE more generally than with plastics specifically. Plastics recycling cannot simply be improved in isolation.

- The recommendations for end consumers concern awareness - of what is electronic waste, and what to do with such waste at end-oflife. The essential issue concerns consumers mistakenly regarding waste as relatively harmless.

- The recommendations for authorities and policy-makers show that huge improvements can be made without revolution or wholesale change. Modest cost changes and the setting of more specific targets could deliver much greater quality without radically affecting the existing value chain. Keeping waste in that value chain is crucial.

\section{- Recyclers are somewhat} dependent on the actions of other stakeholders. In particular, they may be required to bear increased costs, both for treatment itself and for the administration, tracking and monitoring of waste through their systems. They cannot realistically be expected to do this alone; they need co-operation from many other parties, and specific financial drivers arising from policy-makers and/or producers.
- Electronics producers may also be encouraged to consider activities involving some additional costs (design for recycling, customer communication on recycling issues) but indirect benefits could offset some of these costs, and these activities may become absolute regulatory requirements in future. 


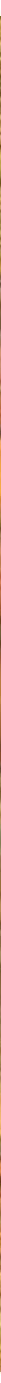




\section{norden}

Nordic Council of Ministers

Ved Stranden 18

DK-1061 København K

www.norden.org

This policy brief on Nordic improvements in collection and recycling of plastic waste is part of the Nordic Prime Minister's overall green growth initiative, The Nordic Region - leading in green growth. Read more in the web magazine Green Growth the Nordic Way at

www.nordicway.org or at www.norden.org/greengrowth 